\title{
Perfil de lesões em atletas brasileiros de rugby em cadeira de rodas
}

http://dx.doi.org/10.11606/1807-5509201800040521

\author{
Daniela Clarissa BAZANELLA* \\ Mariane de Freitas Alves MACHADO* \\ Simone ZATESKO* \\ Audrin Said VOJCIECHOWSKI ${ }^{* *}$ \\ Luize Bueno ARAUJO* \\ Raciele Ivandra Guarda KORELO***
}

*Universidade Federal

do Paraná, Matinhos,

PR, Brasil.

${ }^{* *}$ Departamento de

Educação Física,

Universidade Federal

do Paraná, Curitiba

PR, Brasil.

*** Departamento de Fisioterapia,

Universidade Federal

do Paraná, Curitiba,

PR, Brasil.

\section{Resumo}

0 estudo objetivou verificar o perfil das lesões em atletas brasileiros praticantes de rugby em cadeira de rodas (RCR). Trata-se de pesquisa de corte transversal, com 72 atletas de RCR, distribuídos entre 8 equipes brasileiras. Os dados foram coletados por meio de questionário semiestruturado do tipo recordatório, contemplando caracterização demográfica, esportiva (time, tipo de cadeira para prática esportiva, tempo da prática esportiva, classificação funcional, frequência e duração de treinamento) e das lesões (tipo da lesão, local acometido, mecanismo e momento da lesão, tratamento e afastamento). Os resultados mostraram que $66,67 \%$ dos atletas apresentaram algum tipo de lesão durante a prática esportiva, sendo que a maioria $(75,5 \%)$ ocorreu durante os treinos. Maior acometimento foi em membros superiores, sendo em sua maioria no sistema tegumentar (abrasão, bolha e calo). A tendinite apresentou maior frequência ( $9 \%$ ) dentre as lesões que acometeram o sistema musculoesquelético, seguida por distensão $(3,3 \%)$ e luxação $(2,5 \%)$. Não houve correlação entre a quantidade das lesões e o tempo de prática e/ou classificação funcional. Portanto, nosso estudo revelou de alta incidência de lesões com a prática esportiva, sendo a maior parte delas sem gravidade tendo como agente causal a condução da cadeira de rodas. Assim, evidencia-se a necessidade de estratégias e profissionais habilitados atuando na promoção, prevenção e reabilitação; além do acompanhamento a longo prazo, uma vez que é um esporte considerado novo no cenário brasileiro e que envolve contato físico e níveis elevados de condicionamento físico.

PalavRAS-CHAVE: Esporte adaptado; Lesões esportivas; Esportes para pessoas com deficiências; Deficiência física.

\section{Introdução}

A prática esportiva traz inúmeros benefícios à vida social e à saúde da população em geral, com atenção especial para o incremento de habilidades funcionais em pessoas com deficiências ${ }^{1}$. Assim, o Rugby em Cadeira de Rodas (RCR) foi criado no Canadá, em 1977, e tornou-se esporte paralímpico nos jogos de Sydney, em $2000^{2}$. O esporte pode ser praticado por indivíduos com comprometimento em três ou quatro membros, decorrentes de lesão da medula espinhal (total ou parcial, acima da primeira vértebra torácica, caracterizando a tetraplegia/tetraparesia), síndromes, amputaçáo e/ou deformidades, entre outras ${ }^{3,4}$.
Devido ao grande incentivo a prática do esporte adaptado, a busca pelo RCR se tornou expressiva, sendo considerado atualmente a modalidade paralímpica que mais cresce no mundo, permitindo aos indivíduos com incapacidades competir no esporte em nível de elite ${ }^{2}$. Este crescimento do número de atletas com deficiência e a popularidade dos esportes paralímpicos em todo o mundo, com destaque para o cenário nacional, está em evidência, principalmente após o Brasil sediar os Jogos Paralímpicos RIO 20165.

O RCR chegou ao Brasil em 2005, devido a realização dos Jogos Mundiais em Cadeira de Rodas. 
Sua prática foi oficializada em 2008, com a fundação da Associação Brasileira de Rugby em Cadeira de Rodas (ABRC). Desde então, o interesse das pessoas com deficiência em realizá-lo está aumentando, uma vez que possibilita a participação de pessoas com tetraplegia, que anteriormente dificilmente se enquadravam nos critérios dos esportes adaptados ${ }^{6,7}$. Como efeito desta procura, a melhora da performance, tanto individual quanto coletiva, tem se desenvolvido com o objetivo de alcançar melhores resultados para o atleta e também para as equipes. Para tanto, faz-se necessário o aumento nas cargas de treinamentos e competições, provocando o aumento dos índices de lesóes como consequência do esporte nesses atletas ${ }^{4,8}$.

O RCR assemelha-se ao rugby tradicional praticado por atletas hígidos, uma vez que estas modalidades possuem objetivos parecidos e ambas envolvem um forte contato físico e níveis elevados de condicionamento físico. Contudo, para o RCR ainda é necessário a agilidade para realizar o manuseio da bola, acelerar, frear e direcionar a cadeira de rodas .

Estudo publicado recentemente ${ }^{10}$ afirma que o rugby tradicional possui risco relativamente alto de ocorrência de lesóes, sendo a maioria (aproximadamente 80\%) resultado do contato físico como colisóes e movimento de ataque, que ocorrem devido a um padrão de movimento disfuncional e/ou técnica inadequada do jogador. Enquanto as lesões classificadas como não-contato, ocorrem geralmente nos tecidos moles e representam aproximadamente $20 \%$ do total de lesóes. Estas lesóes são resultandes de cargas de treinamento excessivas, sendo os atletas com mau controle neuromuscular e/ou desequilíbrios da musculatura de estabilizadora de tronco, os mais susceptíveis, devido as cargas repetitivas impostas por padrôes de movimento disfuncionais.

Pesquisas anteriores ${ }^{11}$ demonstraram que as taxas de lesões no esporte paralímpico geralmente são mais elevadas quando comparadas a prática em atletas hígidos. Os para-atletas possuem condiçóes médicas pré-existentes complexas e estão expostos a cargas biomecânicas repetitivas e, às vezes, impróprias em suas atividades de vida diária ${ }^{12}$. Porém, a revisão realizada por FAGHER e LEXELL ${ }^{11}$ mostra que há poucos estudos sobre padróes de lesão, fatores de risco e estratégias de prevenção de lesóes em atletas com deficiência.

Nos Jogos Paralímpicos Rio 2016 foi prevista a realização de um estudo de vigilância de lesóes e doenças pelo Comitê Paralímpico Internacional com intuito de fornecer dados epidemiológicos sobre sua ocorrência durante o período de competição ${ }^{13}$, porém, até o presente momento, os resultados ainda não foram publicados.

BAUERFEIND et al..$^{14}$ analisaram a etiologia das lesóes e os principais locais acometidos em atletas de RCR de um time polonês. Os autores encontraram ocorrência de sobrecarga muscular (42\%) na mão e nas laterais do tronco, abrasão (29\%) e tensões musculares (19\%) nos músculos do braço e cintura escapular, contusão (8\%) e subluxação (2\%) na mão. O estudo de FAGHER e LEXELL ${ }^{11}$ corrobora estes achados ao afirmar que as lesóes dos membros superiores são mais prevalentes em atletas de cadeira de rodas.

No entanto, não foram encontrados estudos relacionados à ocorrência de lesóes decorrentes da prática do RCR em atletas brasileiros. Além disso, a falta de identificaçáo dos fatores de risco às lesóes, somado ao conhecimento ainda limitado dos efeitos fisiológicos induzidos pelo RCR, dificultam a determinação de medidas preventivas quanto ao estabelecimento de programas de treinamento adequados e tratamentos específicos.

Sendo assim, o objetivo do presente estudo foi analisar o perfil das lesóes relatadas por atletas praticantes de Rugby em Cadeira de Rodas, de 8 equipes brasileiras, com o intuito de identificar os fatores de risco ao seu aparecimento e verificar se há associação entre o tempo de prática e categoria funcional com o número de lesões relatadas pelos atletas.

\section{Método}

Trata-se de pesquisa descritiva do tipo levantamento de corte transversal único. O estudo seguiu a Resoluçáo 466/12 do Conselho Nacional de Saúde e foi aprovado pelo Comitê de Ética em Pesquisa do Setor de xxx (Parecer 212.5xx). As coletas foram realizadas durante o VI Campeonato Brasileiro de Rugby em Cadeira de Rodas, no município de xxx, xx.
O plano amostral definido foi censo, ou seja, aplicação do questionário com a totalidade de praticantes do esporte no Brasil, sendo que no cenário nacional, a Associação Brasileira de Rugby em Cadeira de Rodas ${ }^{15}$ (ABRC) relatou existir 15 associaçóes e movimentos filiados no período da coleta, com cerca de 100 atletas credenciados em 2013. 
Foram incluídos atletas do RCR, de ambos os sexos, que participaram do VI Campeonato Brasileiro de RCR, no ano de 2013. Os critérios de exclusão foram: atletas que não concordaram em assinar o termo de consentimento livre e esclarecido (TCLE), menores de 18 anos, atletas inelegíveis para prática do RCR e os que não preencheram por completo as informaçóes do questionário. Estavam presentes 74 atletas no Campeonato, sendo que destes, 72 foram inclusos no trabalho e apenas 2 excluídos (um atleta por ser menor de idade e um atleta considerado inelegível para a prática do RCR pela Comissão de Classificação Funcional).

Os participantes responderam um questionário semiestruturado que contemplava itens para caracterização demográfica e clínica da amostra, caracterização do esporte, sobre o tipo e mecanismo de lesão causada pelo esporte. $\mathrm{O}$ questionário, do tipo recordatório, foi aplicado por um pesquisador previamente treinado e coletado de forma individual, para evitar constrangimentos ao responder e manter sigilo dos dados respondidos. Dúvidas que surgiram no momento dos questionamentos foram esclarecidas para evitar desconfortos e respostas errôneas.

Para a caracterização demográfica e clínica da amostra, as questôes referiam-se a idade, sexo, profissáo, etiologia da deficiência e uso de equipamento auxiliar para locomoção. Para a caracterização do esporte, foi questionado o time de RCR a qual pertenciam, tipo de cadeira para prática esportiva, tempo da prática esportiva, classificação funcional no Rugby, além da frequência e duração de treinamento.

Quanto aos itens que envolviam a lesão causada pelo esporte, foram levantados os locais anatômicos de acometimento (ombro, cotovelo, punho, mão, quadril, joelho, tornozelo e pé) e o tipo de lesão definidos em estudo ${ }^{16}$ de revisão bibliográfica sobre lesôes desportivas, podendo ser contusão, distensão, tendinite, entorse, luxação, subluxação, abrasão, bolha, calo, fratura e sem diagnóstico.

Ainda foram contempladas questóes referentes ao mecanismo da lesão (colisão cadeira-cadeira, queda, entre outros), lado que ocorreu a lesão, se a mesma ocorreu no treino ou em competição, se houve afastamento da prática esportiva, se houve tratamento no período da lesão e qual foi o tratamento e, se no momento da avaliação a lesão ainda provocava alguma dor, sua frequência e intensidade.

A análise estatística ${ }^{17}$ procedeu-se com a utilização do software R. Em sua totalidade, os dados foram submetidos ao teste de Kolmogorov-Smirnov para testar a normalidade de distribuição. As variáveis nominais e/ou ordinais foram descritas em frequência absoluta e percentual, já as variáveis numéricas foram descritas em média e desvio padrão. Para analisar se o tempo de prática influenciou a quantidade de lesóes utilizou-se o Coeficiente de Correlação de Spearman. Para verificar a influência da categoria funcional (baixa e alta) na quantidade de lesóes utilizou-se o teste de Tendência Linear. O nível de significância foi fixado em $\mathrm{p}<0,05$.

\section{Resultados}

\section{Características demográficas e clínicas}

A amostra foi constituída de 72 indivíduos, distribuídos entre 8 equipes de RCR vinculadas à

ABRC, faixa etária entre 19 a 43 anos. As características demográficas e clínicas dos participantes estão apresentadas na Tabela 1 .

TABELA 1 - Características demográficas e clínicas dos participantes (n = 72)

\begin{tabular}{lc}
\hline Características demográficas e clínicas & $\begin{array}{c}\text { Média } \pm \text { DP } \\
\mathbf{n}(\%)\end{array}$ \\
\hline Idade (anos, média \pm DP) & $31,2 \pm 5,7$ \\
Gênero (n,\%) & \\
$\quad$ Feminino & $1(1,4)$ \\
$\quad$ Masculino & $71(98,6)$ \\
Profissão (n,\%) & \\
\hline
\end{tabular}

Continua 
Continuação

TABELA 1 - Características demográficas e clínicas dos participantes $(n=72)$

\begin{tabular}{lc}
\hline Características demográficas e clínicas & Média \pm DP \\
$\mathbf{n}(\%)$
\end{tabular}

\section{Características esportivas}

Os 72 atletas participantes foram categorizados de acordo com o time ao qual pertenciam, o tempo de prática, a classificaçáo funcional, o tipo de cadeira que utilizavam (ataque ou defesa), a procedência da cadeira (nacional ou internacional), se a cadeira foi feita sob medida, a frequência e a duração do treinamento, e ainda, se praticam outro tipo de modalidade esportiva (Tabela 2).

TABELA 2 - Caracterização esportiva dos participantes $(\mathrm{n}=72)$

\begin{tabular}{lc}
\hline Características esportivas & $\begin{array}{c}\text { Média } \pm \text { DP } \\
\mathbf{n}(\%)\end{array}$ \\
\hline Número de participantes por time $(\mathrm{n}, \%)$ & \\
Time 1 & $10(13,9)$ \\
Time 2 & $10(13,9)$ \\
Time 3 & $10(13,9)$ \\
Time 4 & $10(13,9)$ \\
\hline
\end{tabular}


Continuação

TABELA 2 - Caracterização esportiva dos participantes $(n=72)$

\begin{tabular}{|c|c|}
\hline Características esportivas & $\begin{array}{c}\text { Média } \pm \text { DP } \\
\text { n (\%) }\end{array}$ \\
\hline \multicolumn{2}{|l|}{ Número de participantes por time $(\mathrm{n}, \%)$} \\
\hline Time 5 & $9(12,5)$ \\
\hline Time 6 & $8(11,1)$ \\
\hline Time 7 & $8(11,1)$ \\
\hline Time 8 & $7(9,7)$ \\
\hline \multicolumn{2}{|l|}{ Tempo de prática do Rugby (n, \%) } \\
\hline 0 a 2 anos & $31(43,1)$ \\
\hline 2 a 4 anos & $26(36,1)$ \\
\hline 4 a 6 anos & $12(16,7)$ \\
\hline 6 ou mais anos & $3(4,2)$ \\
\hline \multicolumn{2}{|l|}{ Classificação funcional (n, \%) } \\
\hline 0.5 & $20(27,8)$ \\
\hline 1.0 & $6(8,3)$ \\
\hline 1.5 & $8(11,1)$ \\
\hline 2.0 & $20(27.8)$ \\
\hline 2.5 & $9(12,5)$ \\
\hline 3.0 & $6(8,3)$ \\
\hline 3.5 & $2(2,8)$ \\
\hline Não soube informar & $1(1,4)$ \\
\hline \multicolumn{2}{|l|}{ Tipo de cadeira (n, \%) } \\
\hline Defesa & $38(52,8)$ \\
\hline Ataque & $34(47,2)$ \\
\hline \multicolumn{2}{|l|}{ Procedência da cadeira } \\
\hline Nacional & $47(65,3)$ \\
\hline Internacional & $25(34,7)$ \\
\hline \multicolumn{2}{|l|}{ Cadeira feita a partir das medidas do atleta (n, \%) } \\
\hline Sim & $49(68,1)$ \\
\hline Não & $23(31,9)$ \\
\hline \multicolumn{2}{|l|}{ Atleta pratica outro esporte $(n, \%)$} \\
\hline Sim & $22(30,6)$ \\
\hline Não & $50(69,4)$ \\
\hline \multicolumn{2}{|l|}{ Frequência do treino } \\
\hline $2 \mathrm{x} /$ semana & $17(23,6)$ \\
\hline $3 \mathrm{x} /$ semana & $49(68,1)$ \\
\hline $4 \mathrm{x} /$ semana & $2(2,8)$ \\
\hline $5 \mathrm{x} /$ semana & $4(5,6)$ \\
\hline Duração diária do treino (horas, média \pm DP) & $2,5 \pm \mathbf{0 , 7}$ \\
\hline
\end{tabular}

Em média os atletas de RCR possuem 2 anos e 8 meses de prática, com um intervalo que varia entre um mês até oito anos. Atletas com classificação funcional 0.5 e 2.0 são os mais comuns e correspondem a $27,8 \%$ cada. O tipo de cadeira utilizada, defesa ou ataque, tem pouca variação, sendo a procedência mais comum, cadeiras de origem nacional $(65,3 \%)$ e feitas a partir das medidas dos atletas $(68,1 \%)$. Quanto à frequência de treinamento, a maioria $(68,1 \%)$ dos atletas treinam três vezes na semana. Porém, no período próximo a competiçóes, $62,5 \%$ dos atletas declaram que esses treinos variam em quantidade, intensidade e duração. 
Perfil das lesóes decorrentes da prática do RCR

Dos 72 atletas entrevistados, $66,67 \%$ (48) relataram ter sofrido algum tipo de lesão no decorrer da prática esportiva. Dos 48 atletas acometidos por lesóes, 12,9\% relatam ter sofrido apenas uma lesão, 29,5\% duas lesōes, $4,9 \%$ três lesóes, $29,5 \%$ quatro lesōes, $17,2 \%$ sete lesóes e 6,5\% sofreu 8 lesóes, totalizando 100\% das lesôes. Sendo assim, ficou registrado a ocorrência de 122 lesóes entre os 48 participantes do estudo. Os locais de acometimento são descritos na Tabela 3.

$\mathrm{Na}$ Tabela 3 observa-se que a maioria das lesóes ocorreu no sistema tegumentar $(76,3 \%)$, seguido do sistema musculoesquelético (18\%), sendo que $5,7 \%$ não tiveram o diagnóstico definido. Dentre as lesões do sistema tegumentar, a abrasão ocorreu com maior frequência (29,5\%), sendo o cotovelo $(14,8 \%)$ o local de maior acometimento. Dentre as lesóes do sistema musculoesquelético, a tendinite acometeu o maior número de atletas (9\%).

$\mathrm{O}$ agente causal (Tabela 4) mais comum das lesóes do sistema tegumentar e musculoesquelético ocorreram durante a conduçáo da cadeira de rodas. Dentre as lesóes que ocorreram pela condução, as mais comuns foram calo $(27,9 \%)$, seguidas de abrasão (17.2\%) e bolha (17,2\%). As colisões resultaram, de forma igualitária, na ocorrência de luxaçóes $(0,8 \%)$, entorse $(0,8 \%)$ e fratura $(0,8 \%)$.

Enquanto as lesóes que ocorreram por mau posicionamento (acomodação do atleta na cadeira) foram bolha $(1,6 \%)$, luxação $(0,8 \%)$ e contusão $(0,8 \%)$. Ainda, a maioria das lesóes $(75,5 \%)$ ocorreu durante os treinos, enquanto a incidência de lesóes em competiçóes foi menor (34,4\%).

Apenas 22,9\% dos atletas de RCR se afastaram da prática esportiva após as lesóes, com média de 2,29 semanas de afastamento. Dentre os atletas que sofreram lesões, $58,1 \%$ necessitaram realizar algum tipo de tratamento ( $46,5 \%$ curativos, 30,2\% fisioterapia, $13,95 \%$ tratamento medicamentoso e $9,30 \%$ imobilização). Vinte e um por cento dos atletas relataram sofrer de dor crônica em decorrência da lesão, com uma média de intensidade de dor na escala EVA (escala visual analógica) de 4,73, sendo que em $41,67 \%$ a dor está presente o tempo todo.

Não houve correlação significativa entre a quantidade de lesóes e o tempo total de treino de cada atleta $(r=0,084, \mathrm{p}=0,47)$. Também não foi constatado influência da categoria funcional do atleta com a quantidade de lesóes $(r=-0,068, \mathrm{p}=0,56)$.

TABELA 3 -Descrição da distribuição absoluta (n) e relativa (\%) do tipo de lesão por região anatômica de ocorrência $(\mathrm{n}=122)$

\begin{tabular}{|c|c|c|c|c|c|c|c|c|c|}
\hline & Ombro & Cotovelo & Punho & Máo & Quadril & Joelho & Tornozelo & Pé & Total \\
\hline \multicolumn{10}{|l|}{$\begin{array}{l}\text { Músculo } \\
\text { esqueléticas }\end{array}$} \\
\hline Tendinite & $4(3,3)$ & $3(2,5)$ & $3(2,5)$ & - & - & - & - & $1(0,8)$ & $11(9)$ \\
\hline Distensão & $3(2,5)$ & $1(0,8)$ & - & - & - & - & - & - & $4(3,3)$ \\
\hline Luxação & $1(0,8)$ & - & - & $2(1,6)$ & - & - & - & - & $3(2,5)$ \\
\hline Contusão & - & - & $1(0,8)$ & $1(0,8)$ & - & - & - & - & $2(1,6)$ \\
\hline Entorse & - & - & - & $1(0,8)$ & - & - & - & - & $1(0,8)$ \\
\hline Fratura & - & - & - & $1(0,8)$ & - & - & - & - & $1(0,8)$ \\
\hline Subluxação & - & - & - & - & - & - & - & - & 0 \\
\hline \multicolumn{10}{|l|}{ Tegumentar } \\
\hline Abrasão & $1(0,8)$ & $18(14,8)$ & $2(1,6)$ & $13(10,7)$ & $2(1,6)$ & - & - & - & $36(29,5)$ \\
\hline Calo & - & $2(1,6)$ & $2(1,6)$ & $30(24,6)$ & - & - & - & - & $34(27,9)$ \\
\hline Bolha & - & - & - & $21(17,2)$ & - & - & $2(1,6)$ & - & $23(18,9)$ \\
\hline $\begin{array}{l}\text { Sem } \\
\text { diagnóstico }\end{array}$ & $3(2,5)$ & - & $3(2,5)$ & - & $1(0,8)$ & - & - & - & $7(5,7)$ \\
\hline Total & $\begin{array}{c}12 \\
(9,9)\end{array}$ & $24(19,7)$ & $11(9)$ & $69(56,5)$ & $3(2,5)$ & - & $2(1,6)$ & $1(0,8)$ & $\begin{array}{c}122 \\
(100)\end{array}$ \\
\hline
\end{tabular}


TABELA 4 - Descrição da distribuição absoluta (n) e relativa (\%) do tipo de lesão por agente etiológico (n = 122)

\begin{tabular}{lcccccc}
\hline & Mau posicionamento & Conduçáo & Frenagem & Quedas & Colisão & Total \\
\hline Musculoesquelética & & & & & & \\
Tendinite & - & $11(9)$ & - & - & - & $11(9)$ \\
Distensão & - & $4(3,3)$ & - & - & - & $4(3,3)$ \\
Contusão & $1(0,8)$ & $1(0,8)$ & - & - & - & $2(1,6)$ \\
Entorse & - & - & - & - & $1(0,8)$ & $1(0,8)$ \\
Fratura & - & - & - & - & $1(0,8)$ & $1(0,8)$ \\
Luxação & $1(0,8)$ & $1(0,8)$ & - & - & $1(0,8)$ & $3(2,5)$ \\
Subluxaçáo & - & - & - & - & - & 0 \\
Tegumentar & & & & & & \\
Abrasáo & - & $25(20,5)$ & $10(8,2)$ & $1(0,8)$ & - & $36(29,5)$ \\
Calo & - & $34(27,9)$ & - & - & - & $34(27,9)$ \\
Bolha & $21(17,2)$ & - & - & - & $23(18,9)$ \\
Sem diagnóstico & - & $5(4,1)$ & - & - & $2(1,6)$ & $7(5,7)$ \\
Total & $4(3,3)$ & $102(83,6)$ & $10(8,2)$ & $1(0,8)$ & $5(4,1)$ & $122(100)$ \\
\hline
\end{tabular}

\section{Discussão}

O presente estudo analisou o perfil de lesóes de atletas brasileiros praticantes de RCR. Verificou-se que $66,67 \%$ dos praticantes sofreram alguma lesão decorrente do esporte, sendo que a maioria $(76,3 \%)$ acometeu o sistema tegumentar, em especial as abrasóes; enquanto $18 \%$ acometeu o sistema musculoesquelético, em especial a tendinite.

Enquanto para alguns autores ${ }^{11}$, lesão é considerada qualquer evento que requer atendimento médico ou motive uma ausência em treinamento/competição; o consenso ${ }^{18}$ sobre lesóes no rugby considera-a como qualquer queixa física, causada por transferência de energia que excedeu a capacidade do organismo em manter sua integridade estrutural e/ou funcional, sofrida durante uma partida ou treino, independentemente da necessidade de assistência médica ou do tempo de afastamento das atividades do esporte. Dessa forma, a gravidade da lesáo pode ser classificada de acordo com o tempo durante o qual o atleta fica afastado das atividades, a saber: mínima (2-3 dias), leve (4-7 dias), moderada (8-28 dias) e grave $(>28 \text { dias })^{18}$.

Portanto, nosso estudo revelou que a maioria das lesōes eram mínimas ou leves, pois apenas 22,9\% necessitaram se afastar dos treinos e competições, por um período médio de 14 dias, para náo agravar o quadro patológico, sendo que somente $58,1 \%$ buscou tratamento específico para a lesão. A condução da cadeira de rodas, foi o fator causal predominante para as lesóes de menor gravidade. No entanto, a colisão estava associada a lesóes moderadas e/ou graves, como luxação, entorse e fratura. A maioria das lesóes $(75,5 \%)$ ocorreu durante o treino, sendo que não houve associação estatística da quantidade de lesóes com o tempo de prática do esporte ou com a categoria funcional do atleta.

Neste estudo, dentre os brasileiros praticantes de RCR, constatou-se que a deficiência mais comum foi decorrente de trauma raquimedular $(86,1 \%)$, sendo as outras decorrentes de sequela de poliomielite $(4,2 \%)$, encefalopatia crônica não progressiva $(1,4 \%)$, amputação $(1,4 \%)$ e outras patologias $(6,9 \%)$ como má formação congênita e distrofias musculares. Achado este que corrobora o estudo de BAUERFEIND et al. ${ }^{14}$ com atletas poloneses praticantes de RCR, no qual todos sofreram trauma raquimedular. Isso pode ser justificado pelo fato de que os indivíduos elegíveis para a prática de RCR devem possuir comprometimento em três de quatro de seus membros ${ }^{2}$, o que ocorre nos indivíduos com lesão cervical (tetraplegia/paresia) decorrente do trauma raquimedular, os quais optam pelo RCR uma vez que existem poucas opçóes de prática esportiva para indivíduos com maiores comprometimentos e buscam a prática esportiva como forma de amenizar as complicaçóes decorrentes da lesão na medula espinhal ${ }^{7}$.

Uma vez que os atletas podem possuir incapacidades provenientes de diferentes patologias permanentes e debilitantes, foi criado um sistema de classificação funcional para o esporte, com intuito de garantir a igualdade de representação entre os jogadores da equipe. O sistema é composto por sete categorias que 
variam de 0.5 (classe de jogadores que apresentam maior debilidade, com limitada função em membros superiores) a 3.5 (classe de maior funcionalidade). Desta forma, são permitidos em quadra apenas quatro jogadores com a quantia máxima de 8.0, decorrente do somatório de classificaçóes individuais de cada atleta, mas se caso houver uma mulher em quadra esse máximo de pontos passa a ser $8.5^{2,3}$. No presente estudo, seguindo a classificação funcional, $47,2 \%$ são atletas considerados "ponto baixo" (0.5 a 1.5) e 51,4\% "ponto alto" (2.0 a 3.5).

As diferentes classificaçóes dos atletas permitem diferentes habilidades em campo ${ }^{2}$. O RCR é praticado com bola parecida à do vôlei, em quadra esportiva semelhante à quadra oficial de basquetebol ${ }^{4}$ e possui características comuns a outros esportes: como rugby de campo, basquetebol, futebol americano e hóquei ${ }^{3,7}$. Para a prática são utilizados dois tipos de cadeiras que diferem entre si, por possuírem diferentes acessórios ${ }^{19}$ : ataque (possui para-choque frontal para dificultar que a cadeira fique presa) e defesa (possui acessório frontal para auxiliar o atleta a travar a cadeira do adversário e impedir sua progressáo). No presente estudo, 52,8\% possuía cadeira de defesa e $47,2 \%$ de ataque.

Nossos achados demonstraram que a maioria $(68,1 \%)$ dos atletas neste estudo, possuem cadeiras confeccionadas com medidas individualizadas e ergonomicamente adaptadas, de procedência nacional $(65,3 \%)$. Estudo anterior ${ }^{20}$ que discorre sobre os aspectos ergonômicos de configuração das cadeiras de rodas para a melhor performance da prática do esporte, afirma que determinadas configuraçóes de cadeiras de rodas podem estar associadas a risco aumentado de lesões, além de elevar a demanda fisiológica da propulsão na cadeira pelo atleta. Assim sendo, no RCR e aconselhável que a altura do assento não exceda $53 \mathrm{~cm}$ e as rodas principais devem ser protegidas por para-raios e possuir diâmetro máximo de $70 \mathrm{~cm}$.

Desta forma, a partir deste estudo, 48 (66,67\%) dos 72 atletas brasileiros participantes, alegaram algum tipo de lesão. Mesmo o RCR sendo considerado um esporte com forte contato físico, verifica-se neste estudo que os atletas náo apresentaram lesóes graves, sendo que a maior parte das lesóes verificadas foi decorrente de inadequado manuseio da cadeira de rodas e má acomodação do atleta na mesma, resultando apenas em abrasōes e bolhas. Já as lesões resultantes de contato físico em disputas de bola, por exemplo, parecem ser menos incidentes, apesar da característica do esporte.

Em estudo $^{21}$ realizado durante os Jogos Paralímpicos de Londres, em 2012, a taxa de incidência em atletas de RCR foi de $16,3 \%$, no qual os 79 atletas participantes tiveram 18 lesóes, sendo classificada como a quinta modalidade mais propensa a lesões. As maiores razóes de incidências foram relatadas no futebol de 5 , halterofilismo, goalball e esgrima de cadeira de rodas. Interessantemente os autores demonstraram que os dados paralímpicos reveleram que o RCR foi menos lesivo do que esportes individuais, apesar de possuir maior contato físico. Tais resultados corroboram os achados do presente estudo, no qual náo houve relato de lesóes graves.

Diante das diferentes habilidades trabalhadas e a grande interação social que a prática do esporte proporciona, fato interessante foi observado na populaçáo estudada, onde $30,6 \%$ dos participantes relataram praticar outro esporte além do RCR. No entanto, por mais que a prática de RCR proporcione diferentes benefícios ao praticante, sabe-se que com os treinos e competiçóes, os atletas estáo expostos a sofrer lesão decorrente do esporte ${ }^{22}$. Este fato pode ser justificado por ser o único esporte de contato completo jogado por atletas com deficiências ${ }^{2}$, que gera grandes impactos e exige a realização de grandes esforços ${ }^{22}$, fato não comprovado neste estudo onde a incidência de lesão musculoesquelética foi baixa, sugerindo que sua prática parece ser segura.

No presente estudo, como 30,5\% dos atletas praticavam outro esporte além do RCR. A incidência das lesóes esportivas encontradas poderia estar mais elevada devido a prática de concomitante de outros esportes, pois, além do esforço exigido pelo RCR, há também a sobrecarga dos treinos e competiçóes da outra modalidade paralímpica que o indivíduo pratica. Apesar desta afirmativa, não foi possível observar correlação entre o tempo de treino e a quantidade de lesôes, justificada pela discrepância do tempo de treinamento entre os atletas.

Ainda, no presente estudo, em relação ao total das lesões 51,6\% acometeram atletas "ponto baixo" e $48,4 \%$ atletas "ponto alto". Desta forma, análises estatísticas revelaram que não houve relação entre a categoria funcional e a quantidade de lesóes. Inicialmente hipotetizamos que as diferentes classes funcionais poderiam estar relacionadas à incidência de lesōes, uma vez que a classificação funcional está estreitamente associada ao volume de atividade (velocidade e distância percorrida) realizada durante uma partida de rugby ${ }^{23}$. Ainda, sabe-se que atletas de classe baixa geralmente possuem funções defensivas e atletas de classa alta, ocupam funçóes de ataque, que requerem habilidades e atividades motoras distintas ${ }^{23}$. Por exemplo, atletas de defesa permanecem por maior tempo em atividades estáticas de baixa velocidade para 
bloquear os adversários; enquanto atletas de ataque necessitam realizar paradas/freqadas bruscas, saídas rápidas para ataque/contra-ataque e retorno do ataque para a defesa, o que leva a uma fricção constante entre pele e cadeira, podendo desencadear maior incidência de lesóes tegumentares. Porém nosso estudo revelou que os atletas de RCR são acometidos por lesóes de forma semelhante, independentemente da classificação funcional apresentada e/ou da habilidade motora exigida em quadra.

Dentre as 122 lesóes relatadas pelos 48 atletas praticantes de RCR foi observado predomínio de lesões em membros superiores (94,2\%), dados semelhantes aos estudos de BAUERFEIND et al. ${ }^{14} \mathrm{e}$ WiLLick et al. ${ }^{21}$ nos quais as lesóes acometeram principalmente musculatura da cintura escapular, do braço, cotovelo e mão; e ombro, cotovelo, punho e mão, respectivamente. Comparativamente ao tênis de mesa praticado por atletas paralímpicos ${ }^{8}$, apesar de toda a diferença biomecânica entre os dois esportes, ambos utilizam predominantemente para sua prática os membros superiores, sendo então justificado que a maior ocorrência das lesóes acometeu ombro (32\%) e coluna (36\%).

No presente estudo a mão foi o local mais acometido para as lesōes do sistema tegumentar (52,5\%) e o ombro foi o local mais acometido por lesóes musculoesqueléticas $(5,8 \%)$. Tal fato pode ser justificado, conforme estudo ${ }^{25,26}$ com atletas de basquetebol em cadeira de rodas, pois, assim como no RCR, a região dos membros superiores, principalmente os ombros, são as mais utilizadas para passes específicos da modalidade, para locomoção geralmente em alta velocidade, para mudar o direcionamento da cadeira e manter o controle do tronco na mesma. Em contrapartida, estudo anterior ${ }^{27}$ verificou a incidência de lesões em ombro em cadeirantes (atletas ou não atletas) e constatou que a participação em modalidades esportivas não influenciou no risco de lesóes durante a prática esportiva, sugerindo que lesóes em extremidades superiores em atletas podem ser decorrentes das atividades de vida diária.

As lesóes no sistema tegumentar foram as mais comuns no presente estudo, e elas ocorreram mais comumente devido a condução da cadeira de jogo $(65,4 \%)$, frenagem $(8,1 \%)$ e mau posicionamento $(1,6 \%)$, pois durante uma partida de RCR os atletas conduzem a cadeira de jogo com rapidez e necessitam realizar frenagem, dribles e passes com a mesma destreza, exigindo assim um contanto entre e a pele e a roda muito constante ${ }^{24}$.

No presente estudo foi observado que do total das lesóes tegumentares, $29,5 \%$ foram abrasōes, $27,9 \%$ calos e 18,9\% bolhas. Divergente aos resultados deste estudo, BAUERFEIND et al. ${ }^{14}$ encontraram apenas $6 \%$ de casos de abrasão nos atletas de RCR, justificado pelo fato dos atletas utilizarem adequadamente o equipamento de proteção (luvas de borracha) nas mãos. Em atletas praticantes de handebol em cadeira de roda ${ }^{28}$ também foi observado grande número de lesôes no sistema tegumentar (39,5\% calos e 9,3\% abrasóes) e desses atletas, 22,2\% relataram que essas lesóes ocorreram pela condução da cadeira de jogo, dado semelhante ao presente estudo. $\mathrm{O}$ mesmo autor remete que o aparecimento de lesôes no sistema tegumentar se dá pelo fato de que os atletas do handebol necessitam realizar paradas/freadas bruscas, saídas rápidas para ataque/contra-ataque e retorno do ataque para a defesa, o que leva a uma fricçáo constante entre pele e cadeira, fundamentos semelhantes aos do RCR.

VITAL et al. ${ }^{8}$ identificaram que a maior prevalência de lesóes de atletas paralímpicos são de origem musculoesquelética. No presente estudo, as lesóes musculoesquelética (18\%) foram o segundo tipo mais comum de lesões, ficando atrás das lesôes tegumentares (76,3\%). Dentre as lesóes musculoesqueléticas neste estudo, destaca-se o aparecimento de tendinites (9\%), distensão $(3,3 \%)$, luxaçáo $(2,5 \%)$, contusão $(1,6 \%)$ e em menor incidência entorse $(0,8 \%)$ e fratura $(0,8 \%)$. Estudo recente ${ }^{14}$ encontrou apenas $2 \%$ de lesôes do tipo escoriação e contusão em membros inferiores, achado semelhante ao do presente estudo, alegando este pequeno número devido à proteção (para-choques) existente na cadeira de rugby. Em estudo ${ }^{28}$ realizado com jogadores de handebol em cadeira de rodas, $23,3 \%$ tiveram lesóes musculares (contraturas, estiramento e distensão), 14\% contusóes, $7 \%$ tendinites, $4,7 \%$ luxaçóes, $2,3 \%$ fraturas e nenhuma entorse, dados que também não se assemelham em atletas de basquete em cadeira de rodas ${ }^{29}$, no qual $35 \%$ das lesões foram contusões, $15 \%$ entorses, $25 \%$ tendinites e bursites e $25 \%$ luxações e fraturas. As divergências de resultados podem ser explicadas devido ao uso de cadeiras de rodas equipadas com suportes de proteçáo (para-choques) no RCR ou o uso de equipamentos de proteção individual, como luvas, o que pode justificar a maior incidência de lesóes musculares e contusóes no handebol e basquetebol.

Ainda, dentre as lesôes musculoesqueléticas, a tendinite foi a de maior incidência entre os atletas de RCR, sendo os locais mais acometidos o ombro $(3,2 \%)$, cotovelo $(2,4 \%)$ e punho $(2,4 \%)$. Tal achado do presente estudo não corrobora evidências anteriores $^{30}$ de que as distensóes são as lesôes mais comuns no mundo do desporto e paradesporto, uma 
vez que a distensão ocorre geralmente em contrações excêntricas, nas quais o músculo está exercendo força e está em alongamento ${ }^{31}$. A partir da dinâmica do RCR este tipo de contração é bastante exigida durante os treinos e competiçóes, dado que explica a distensão $(3,3 \%)$ como segunda lesão musculoesquelética de maior incidência nos atletas deste estudo.

Nos praticantes de RCR desse estudo foi observado prevalência de $2,4 \%$ de luxaçóes, acometendo mão $(1,6 \%)$ e ombro $(0,8 \%)$. Esse tipo de lesão ocorre por traumas e traçóes violentas ou por falta de contenção muscular $^{32}$. Essa falta de contenção e desequilíbrios musculares em membros superiores são comuns em lesados medulares ${ }^{25}$ (86,1\% da populaçáo deste estudo), o que justifica o aparecimento dessas lesóes.

As lesóes nos atletas desse estudo ocorreram com maior frequência durante os treinos $(75,5 \%)$ do que competiçôes $(24,5 \%)$, e, segundo $62,5 \%$ dos atletas, a intensidade, duração e quantidade de treino varia próximo a competiçóes. $\mathrm{O}$ risco de dores musculares e sobrecarga aumentam quando a quantidade de treino é maior que 7 horas semanais ${ }^{29}$, o que explica o aparecimento de lesóes durante os treinos dos atletas do RCR, pois em média esses atletas treinam 2,5 horas por dia e $68,1 \%$ treinam 3 vezes na semana, totalizando assim 7,5 horas de treino semanal, considerando que esses atletas passam mais tempo treinando do que realmente competindo, é provável que essas lesões ocorram mais durante os treinos.

Foi observado neste estudo que apenas $22,9 \%$ dos atletas se afastaram da prática esportiva para realizar o tratamento das lesōes, totalizando em média 2,29 semanas de afastamento. Sugere-se que a volta precoce ao esporte e um tratamento inadequado podem estar favorecendo a recidiva das lesóes. Esse pouco tempo de afastamento pode ser explicado pelo fato de que quanto maior o tempo que o atleta fica parado, maior o descondicionamento físico, ou seja, o condicionamento do atleta é reduzido como consequência do destreinamento ${ }^{33}$. Diferente dos resultados deste estudo, BAuERfeind et al. ${ }^{14}$ identificaram que apenas $4 \%$ do total de lesóes requeriam atendimento médico e apenas duas lesóes levaram ao afastamento temporário dos treinos.

Em relaçáo aos tratamentos procurados pelos atletas do RCR nesta pesquisa os curativos (46,5\%), a fisioterapia $(30,2 \%)$, medicamentos $(13,95 \%)$ e imobilizaçóes $(9,3 \%)$ foram utilizados, dado semelhante ao encontrado em estudo ${ }^{34} \mathrm{com}$ jogadores de vôlei hígidos. Pelo fato de que neste estudo as lesóes do sistema tegumentar foram as mais frequentes, consequentemente os curativos foram os mais utilizados, porém tratamento adequado de fisioterapia para as lesóes do sistema musculoesquelético pode favorecer o retorno à prática esportiva precocemente e diminuir a recidiva dessas lesôes. Então, segundo a literatura ${ }^{16}$, quando os fatores que levam ao aparecimento de lesóes são conhecidos, é possível adotar medidas preventivas e/ou de cura para reduzir os problemas incididos. Essa ideia reforça a necessidade de que profissionais envolvidos com o esporte adaptado devem possuir conhecimento dos fatores causais agravantes para incluírem as açôes preventivas efetivas ${ }^{16}$.

Com base no presente estudo, atletas brasileiros de RCR presentaram maior ocorrência de lesóes em membros superiores, acometendo, principalmente, o sistema tegumentar (abrasão, bolha e calo); enquanto no sistema musculoesquelético foram encontrados mais casos de tendinite, distensões e luxações. Quanto ao mecanismo de trauma a condução da cadeira de rodas foi mais frequente. Em relação ao momento da lesão, o período de treinamento foi mais relatado, sendo que poucos atletas necessitaram de afastamento para tratamento em decorrência da lesão.

Embora o estudo colabore para melhorar a compreensão do perfil das lesóes em praticantes brasileiros de elite de RCR, algumas limitaçóes precisam ser apontadas, como: o instrumento de coleta ser do tipo recordatório, onde alguns indivíduos podem não ter lembrado de todos as lesões as quais foram acometidos; a pesquisa ser realizada durante $o$ campeonato, período que a maioria dos atletas tendem a negligenciar a presença das lesóes para que possam participar do evento; e por fim, pelo fato de náo ter sido abordada lesóes em todos os segmentos corporais excluindo-se regiáo de tronco, cabeça e pescoço.

Sendo assim, sugere-se o desenvolvimento de novos estudos no campo do RCR, com a utilização de questionário validado e adaptado para a população estudada, utilizando como exemplo o consenso para a coleta de dados em estudos de lesóes em jogadores hígidos de rugby ${ }^{18}$ ou com delineamento prospectivo longitudinal que explorem as diferentes lesóes decorrentes da prática esportiva, relacionadas com a preparação física dos atletas, em treinos e competiçóes. Proposta similiar foi publicada recentemente, apresentando um protocolo de estudo epidemiológico prospectivo longitudinal com o objetivo de identificar as lesões decorrentes de esportes paralímipicos, denominado de Sports Related Injuries and Illness in Paralympic Sport Study (SRIIPSS) ${ }^{12}$. Este tipo de estudo poderá contribuir para explorar os fatores de risco e os mecanismos de lesão aos quais os atletas estão suscetíveis, além de correlacionar com o tipo de 
proteção utilizada pelo atleta, pois apesar da crescente popularidade do esporte, as pesquisas ainda são limitadas ${ }^{2,11}$ e com limitações metodológicas.

De acordo com os dados apresentados, pode-se inferir que o principal fator de risco identificado neste estudo está relacionado a falta de medidas preventivas as lesóes do sistema tegumentar durante a condução da cadeira, pois nem o tempo de prática esportiva ou a categoria funcional do atleta não apresentaram associação estatisticamente significativa com a quantidade de lesóes. Nesse sentido, podem ser contempladas a utilizaçáo de equipamentos de proteçâao, prevenção de comportamento de risco e/ou gesto esportivo inadequado, confecção de cadeiras adequadas para a prática e até mesmo a adoçáo de campanhas educativas que abordem a necessidade da inclusão de medidas de redução de riscos de lesão, tais como uso de luvas protetoras, a hidratação adequada da pele e a realizaçáo de aquecimento prévio ao exercício físico, na rotina de treinamento.

\section{Abstract \\ Description of injuries in Brazilian athletes of wheelchair rugby}

The study aimed to determine the description of injuries in Brazilian athletes practicing wheelchair rugby (WR). It is cross-sectional survey, with 72 athletes of WR, distributed among eight Brazilian teams. Data were collected through semi-structured questionnaire recall type, covering demographic characteristics, sports (time, type of chair for sports practice, time of sports practice, functional classification, frequency and duration of training) and injuries (type of injury, involved site, mechanism and time of injury, treatment and removal). The results showed that $66.67 \%$ of the athletes presented some type of injury during sports practice, and the majority $(75,5 \%)$ occurred during training. The local more involvement was in the upper limbs and mostly in cutaneous system (abrasion, blister and callus). Tendinitis had a higher rate (9\%) of the injuries in the musculoskeletal system, followed by distension (3.3\%) and dislocation (2.5\%). There was no correlation between the number of injuries and the length of practice andor functional classification. Therefore, our study revealed a high incidence of injuries with sports practice, most of them being without gravity and their occurred because of the wheelchair's conduction. Thus, it is evident the need for strategies and qualified professionals working in promotion, prevention and rehabilitation; since it is a sport considered new in the Brazilian scenario and that involves physical contact and elevated levels of physical conditioning.

KeYWORDS: Wheelchair sports; Athletic injuries; Sports for persons with disabilities; Physical disability.

\section{Referências}

1. Furmaniuk L, Cywinska-Vasilewska G, Kaczmarek D. Influence of long-term wheelchair rugby on the functional abilities of persons with tetraplegia over a two-year period post-spinal cord injury. J Rehabil Med. 2010;42(7):688-90.

2. Tawse H, Bloom GA, Sabiston CM, Reid G. The role of coaches of wheelchair rugby in the development of athletes with a spinal cord injury. Qual Res Sport Exerc Health. 2012;4(2):206-25.

3. International Wheelchair Rugby Federation. IWFR classification manual. 3rd ed. Delta: IWRF; 2011.

4. Campana MB, Gorla JI, Duarte E, Scaglia AJ, Tavares MCGCF, Barros JF. O rugby em cadeira de rodas: aspectos técnicos e táticos e diretrizes para seu desenvolvimento. Motriz. 2011;17(4):748-57.

5. Silva A, Vital R, Mello MT. Atuação da fisioterapia no esporte paralímpico. Rev Bras Med Esporte. 2016;22(2):157-61.

6. Andrezej A, Zuzanna P, Anna S, Katarzyna G, Monika C. Rugby and physical fitness of people with tetraplegia. J Health Sci. 2013;3(13):372-83.

7. Pena LGS, Costa e Silva AA, Campos LFCC, et al. O "rugby" em cadeira de rodas no âmbito da universidade: relato de experiência da Universidade Estadual de Campinas. Rev Bras Educ Fis Esporte. 2014;28(4):661-9.

8. Vital R, Silva HGPV, Sousa RPA, et al. Lesóes traumato-ortopédicas nos atletas paraolímpicos. Rev Bras Med Esporte. 2007;13(3):165-8. 
9. Flores LJF, Campos LFCC, Gouveia RB, Costa e Silva AA, Pena LGS, Gorla JI. Avaliaçáo da potência aeróbia de praticantes de rugby em cadeira de rodas através de um teste de quadra. Motriz. 2013;19(2):368-77.

10. Tee J, Klingbiel J, Collins R, Lambert M, Coopoo Y. Preseason functional movement screen component tests predict severe contact injuries in professional rugby union players. J Strength Cond Res. 2016;30(11):3194-203.

11. Fagher K, Lexell J. Sports-related injuries in athletes with disabilities. Scand J Med Sci Sports. 2014;24(5):e320-31.

12. Fagher K, Jacobsson J, Timpka T, Dahlström Ö, Lexell J. The Sports-Related Injuries and Illnesses in Paralympic Sport Study (SRIIPSS): a study protocol for a prospective longitudinal study. BMC Sports Sci Med Rehabil. 2016;8(1):28.

13. Blauwet CA, Lexell J, Derman W, et al. The road to Rio: medical and scientific perspectives on Paralympic Games. PM R. 2016;8(8):798-801.

14. Bauerfeind J, Koper M, Wieczorek J, Urbanski P, Tasiemski T. Sports injuries in wheelchair Rugby - a pilot study. J Hum Kinet. 2015;48:123-32.

15. Associação Brasileira de Rugby em Cadeira de Rodas. Home [Internet]. Rio de Janeiro: ABRCR; 2013 [citado 3 fev 2013 ]. Disponível em: http://rugbiabrc.org.br.

16. Simóes NVN. Lesões desportivas em praticantes de atividade física: uma revisão bibliográfica. Rev Bras Fisioter. 2005;9(2):123-28.

17. Field A. Discovering statistics using IBM SPSS Statistics. 4th ed. London: Sage; 2013.

18. Fuller CW, Molloy MG, Bagate C, et al. Consensus statement on injury definitions and data collection procedures for studies of injuries in rugby union. Clin J Sport Med. 2007;17(3):177-81.

19. Melo MT, Wincler C. Esporte paralímpico. São Paulo: Atheneu; 2012.

20. Mason BS, Van der Woude LH, Goosey-Tolfrey VL. The ergonomics of wheelchair configuration for optimal performance in the wheelchair court sports. Sports Med. 2013,43(1):23-38.

21. Willick SE, Webborn N, Emery C, et al. The epidemiology of injuries at the London 2012 Paralympic Games. Br J Sports Med. 2013;47(7):426-32.

22. Campos LFCC, Pena LGS, Gouveia RB, Gatti AMM, Paranhos VMS, Gorla JI. Rugby em cadeira de rodas: aspectos relacionados à caracterização, controle e avaliação. Conexôes. 2013;11(4):72-89.

23. Rhodes JM, Mason BS, Perrat B, Smith MJ, Malone LA, Goosey-Tolfrey VL. Activity profiles of elite wheelchair rugby players during competition. Int J Sports Physiol Perform. 2015;10(3):318-24.

24. Gorla JI, Pena LGS, Campos LFCC, et al. Correlação da classificação funcional, desempenho motor e comparação entre diferentes classes em atletas praticantes de rugby em cadeira de rodas. Rev Bras Cienc Mov. 2012;20(2):25-31.

25. Antonietti LS, Costa RA, Gondo FLB, Oliveira ASB, Chiarello B. Avaliação comparativa em lesados medulares sedentários e praticantes de basquetebol em cadeira de rodas. Rev Neurocienc. 2008;16(2):90-6.

26. Ferreira FA, Bussmann AJC, Greguol M. Incidência de lesões em atletas de basquetebol em cadeira de rodas. Rev Ter Ocup USP. 2013;24(2):134-40.

27. Finley MA, Rodgers MM. Prevalence and identification of shoulder patholy in athletic and nonathletic wheelchair users with shoulder pain: a pilot study. J Rehabil Res Dev. 2004;41(3B):395-402.

28. Borella DR, Storch JA, Almeida LFG, Pires VT, Harnisch GS. Incidência de lesóes esportivas em atletas com deficiência física praticantes de handebol em cadeira de rodas. Rev Sobama. 2012;13(1):7-13.

29. Rocco FM, Saito ET. Epidemiologia das lesóes esportivas em atletas de basquetebol em cadeira de rodas. Acta Fisiatr. 2006;13(1):17-20.

30. Strapasson AM, Baessa DJ, Storch JA, Duarte E. Caracterização das lesões esportivas em atletas de Parabadminton. Conexôes. 2013;11(4):58-71.

31. Clebis NK, Natali MRM. Lesóes musculares provocadas por exercícios excêntricos. Rev Bras Cienc Mov. 2001;9(4):47-53.

32. Soares STM. Trabalho preventivo para lesóes de ombro e cintura escapular em atletas amadores de judô. Rev Bras Cienc Mov. 2003;11(1):29-34.

33. Melchiorri G, Ronconi M, Triossi T, et al. Detraining in young soccer players. J Sports Med Phys Fitness. 2014;54(1):27-33.

34. Santos SG, Piucco T, Reis DC. Fatores que interferem nas lesóes de atletas amadores de voleibol. Rev Bras Cineantropom Desempenho Hum. 2007;9(2):189-95.

\begin{tabular}{r|l} 
ENDEREÇO & Recebido para publicação: 14/05/2016 \\
Audrin Said Vojciechowski & 1a. Revisão: 04/11/2016 \\
Rua Coração de Maria & 2a. Revisão: 30/01/2017 \\
9281531-980 - Curitiba - PR - BRASIL & 3a. Revisão: 14/o3/2017 \\
e-mail: asaidvoj@gmail.com & Aceito: 28/03/2017
\end{tabular}

